\title{
Non-Equilibrium Passive Sampling of Hydrophobic Organic Contaminants in Sediment Pore-Water: PCB Exchange Kinetics
}

\section{Yongju Choi $^{\mathrm{a}}{ }^{*}$, Yanwen Wu ${ }^{\mathrm{b}}$, Richard G. Luthy ${ }^{\mathrm{b}}$, Seju Kang}

${ }^{\mathrm{a}}$ Department of Civil and Environmental Engineering, Seoul National University, Seoul 08826, Republic of Korea

${ }^{\mathrm{b}}$ Department of Civil and Environmental Engineering, Stanford University, Stanford, California 94305-4020, United States

* Corresponding author. Tel.: +82 2880 7376; fax: +82 2873 2684; E-mail address: ychoi81@snu.ac.kr (Y. Choi).

Postal address: 35-307, Seoul National University, 1 Gwanak-ro, Gwanak-gu, Seoul 08826, Republic of Korea 


\begin{abstract}
This study investigates the isotropic exchange kinetics of PCBs for polyethylene (PE) passive samplers in quiescent sediment and develops a novel non-equilibrium passive sampling method using PE with multiple thicknesses. The release and uptake kinetics of PCBs in quiescent sediment are reproduced by a 1-D diffusion model using sediment diffusion parameters fitted with the data from actual measurements. From the sediment diffusion parameters observed for uptake and release kinetics, it is seen that the uptake kinetics are distinctly slower than the release kinetics, most likely because of the sorption-desorption hysteresis of PCBs in the study sediment. Despite the presence of the anisotropic PCB exchange kinetics, a performance reference compound (PRC)-based method, which is grounded on the assumption of isotropic exchange kinetics, estimated the freely dissolved aqueous concentrations $\left(\mathrm{C}_{\text {free }}\right)$ of PCBs in sediment pore-water with less than a factor of two error for the study sediment. The novel method developed in this study using PE with multiple thicknesses also gives reasonable estimates of $\mathrm{C}_{\text {free, }}$, demonstrating its potential as another option for non-equilibrium passive sampling for hydrophobic organic contaminants in sediment pore-water.
\end{abstract}

Key words: Non-equilibrium passive sampling; Polyethylene; Freely dissolved concentration; Multiple thicknesses; PCB 


\section{Introduction}

Passive sampling using organic polymers is gaining acceptance as a tool to determine freely dissolved aqueous concentrations $\left(\mathrm{C}_{\text {free }}\right)$ of hydrophobic organic contaminants (HOCs) in sediments [1]. Recent works demonstrate the applicability of polyethylene (PE), polyoxymethylene (POM), and polydimethylsiloxane (PDMS) for reliable determination of $\mathrm{HOC}_{\text {free }}$ in sediment [2-5]. Once equilibrium is established among the sampler, sediment, and its pore-water, $\mathrm{C}_{\text {free }}$ can be calculated using the sampler concentration and the sampler-water partitioning coefficient for a target analyte $[1,6]$.

Non-equilibrium passive sampling techniques are often required to determine HOC $\mathrm{C}_{\text {free }}$ when samplers are deployed in situ [1]. Studies showed that exposure times of months to years may be needed for establishing equilibrium between the field-deployed passive samplers and the sediment for highly hydrophobic compounds $[1,7,8]$. The current non-equilibrium passive sampling methods rely on the use of performance reference compounds (PRCs) to estimate the extent of equilibrium attained within a sampler [1, 8]. PRCs are selected among the compounds that are analytically noninterfering and have similar chemical properties as target analytes [1]. These compounds are embedded into the sampler prior to exposure and the amount of the compounds released during exposure is analyzed to determine the percentage of equilibrium for target analytes.

The basic assumption of PRC-based methods is the isotropic exchange kinetics of HOCs for a passive sampler [9]. In other words, the methods assume that the uptake kinetics into a sampler is identical to the release kinetics out of the sampler for the same HOC. If this assumption is valid, the uptake kinetics of a target analyte can be estimated 
from the observed release kinetics of a PRC with corrections to account for the difference in chemical properties between the PRC and the target analyte [1]. However, studies validating the assumption of isotropic exchange kinetics for passive samplers deployed in sediments are limited in the literature. Apell and Gschwend [10] argued that the isotropic exchange kinetics was valid under quiescent conditions for the sediment sample they used based on the observation that the equilibrium PE concentrations calculated by a PRC-based method were not significantly different from the PE concentrations directly measured by equilibrium sampling in a sediment slurry. On the other hand, a more recent study by Bao et al. [11] observed slower PRC release rates than the target analyte uptake rates for dichlorodiphenyltrichloroethanes (DDTs) and polychlorinated biphenyls (PCBs) using PDMS fibers contacted with sediment under quiescent conditions. It is necessary to further investigate the validity of the assumption of isotropic exchange kinetics by more closely examining the contaminant exchange behavior involved in both directions (i.e., from sediment to sampler and from sampler to sediment), and using additional sets of sediments and contaminants.

Several studies applied polymeric passive samplers with multiple thicknesses to determine $\mathrm{HOC} \mathrm{C}_{\text {free. }}$. In most cases, passive samplers with two or more thicknesses were used to examine whether equilibrium was established [12-18]. At equilibrium between passive samplers and the contacted sediment, the concentration in passive samplers with different thicknesses should be identical as long as the sampler-water partitioning coefficients are the same. Use of multiple passive sampler thicknesses to assess the kinetics of sampler uptake was demonstrated in a report by Reible and Lotufo [19] and further published in a peer-reviewed article by Lampert et al. [20]. However, the use of 
the data obtained from PDMS fibers with different thicknesses for PAHs in their study was limited to supplementing data obtained by PRC measurements [20]. To our knowledge, no methods have been suggested to use passive samplers with multiple thicknesses as an independent method of non-equilibrium sampling to determine $\mathrm{C}_{\text {free }}$ in sediment pore-water.

The objectives of this study are to assess whether the assumption of isotropic exchange kinetics is valid and to develop a novel non-equilibrium passive sampling method using PEs with multiple thicknesses, which is applicable in cases when the assumption is not valid. PCB uptake and release kinetics for PEs with three different thicknesses are examined in laboratory sediment microcosms under quiescent conditions. The experimental results are used to validate two currently available passive sampler kinetic models. The model that better describes the experimental data is used to assess the potential anisotropy in PE exchange kinetics and to develop a method using PE with multiple thicknesses.

\section{Materials and methods}

\subsection{Materials}

Low density polyethylene (PE) was collected from two manufacturers. PEs with thicknesses of 17, 51, and $102 \mu \mathrm{m}$ were obtained from Husky Plastics (Thornhill, ON). PE with a thickness of $51 \mu \mathrm{m}$ was obtained from Brentwood Plastics (St. Louis, MO). The PEs were cleaned by agitating with hexane for $24 \mathrm{hr}$, then with acetone for $30 \mathrm{~min}$ and deionized water for 30 min prior to use as described in Choi et al. [21]. PCB- 
impacted sediment was collected from a U.S. Superfund site at Hunters Point Shipyard, San Francisco Bay, California. The sediment sample was analyzed in a previous study [22] to have a total PCB concentration of $1.09 \mathrm{mg} \mathrm{kg}^{-1}$ with penta- to heptachlorobiphenyls as major constituents.

\subsection{PCB spiking to PE.}

PEs were loaded with PCB congeners 29 (tri-), 69 (tetra-), 103 (penta-), 155 (hexa-), and 192 (hepta-chlorinated) prior to exposure to the PCB-contaminated sediment. These congeners were used to study the PCB release kinetics from PE as they were not detectable and did not analytically interfere with any detectable congeners in the study sediment. PEs with 17, 51, and $102 \mu \mathrm{m}$ thicknesses from Husky Plastics and $51 \mu \mathrm{m}$ thickness from Brentwood Plastics were added into a bottle containing a 80/20 methanol/water solution. The PE-water partitioning coefficients $\left(\mathrm{K}_{\mathrm{PE}-\mathrm{w}}\right)$ for the $51 \mu \mathrm{m}$ Brentwood PE were determined by Choi et al. [23] for all PCB congeners studied in this work. Thus, the $51 \mu \mathrm{m}$ Brentwood PE was used as a reference to estimate the $\mathrm{K}_{\mathrm{PE}-\mathrm{w}}$ values for the Husky PEs, which were not available in the literature. Concentrated (1000 or $2000 \mathrm{ng} \mathrm{mL}^{-1}$ ) solutions of each PCB congener were added into the methanol/water solution, and the bottle was rolled at $2 \mathrm{rpm}$ for 17 days for equilibrium. An extended equilibration time was applied compared to 2 days in a previous study by Tomaszewski and Luthy [7] using $51 \mu \mathrm{m}$ PE to ensure equilibrium for the thickest PE (i.e., $102 \mu \mathrm{m}$ ) used in the current work. In theory, equilibration time will double when sampler thickness doubles [24], so 17 days of rolling should be sufficient for equilibration. The 
PCB-preloaded PEs were then retrieved, wiped with Kimwipes to remove solvent, and collected in a $40 \mathrm{~mL}$ vial containing $30 \mathrm{~mL}$ deionized water. The vials were mixed for 24 hours to remove residual methanol from the PE. After the mixing, the PEs were collected, wiped again to remove water, and stored at $4^{\circ} \mathrm{C}$ until use. Three small (ca. $30 \mathrm{mg}$ ) pieces of each type of PEs were cut from the collected batch to determine the preloaded PCB concentrations.

\subsection{PE-sediment equilibria}

The PEs and the PCB-impacted sediment were contacted in a slurry phase to determine equilibrium PE concentrations for sediment-derived PCBs. Approximately $15 \mathrm{mg}$ each of the different types of the PEs were placed in each of triplicate $250 \mathrm{~mL}$ jars. The jars were added with $120 \mathrm{~g}$ dry wt of the PCB-impacted sediment and filled with water with a salinity adjusted to the sediment pore-water value of $30 \mathrm{~g} \mathrm{~L}^{-1}$. The final sediment to water ratio was 1:1.5 (w/w). After dispersing the sediment by vigorous hand mixing, the jars were placed in a horizontal shaker and shaken at $100 \mathrm{rpm}$ for 125 days. The PEs were then collected, wiped clean, and analyzed for PCB concentrations. The residual amounts of the initially spiked PCB congeners in PEs were less than $10 \%$ of the initial amount for all congeners and PE thicknesses, validating that the PEs were close to equilibrium with the sediment for PCB partitioning.

\subsection{Exchange kinetics in quiescent sediment}


The kinetics of PCB uptake into and release from PE were studied using sediment microcosms in a quiescent state. Firstly, $60 \mathrm{~mL}$ jars were half-filled with the PCBimpacted sediment. One of the 17, 51, or $102 \mu \mathrm{m}$ Husky PE pieces cut in $2.5 \mathrm{~cm} \times 2.5 \mathrm{~cm}$ was applied on the sediment in each jar. Care was taken to accomplish complete contact between the PE and the sediment with minimal agitation of the sediment. The jars were then carefully filled to the top with the sediment and stored at $20^{\circ} \mathrm{C}$. After sediment-PE contact times of 1, 4, 16, 64, 132, and 264 days, triplicate jars for each PE thickness were collected and the PEs embedded were sampled for PCB analysis.

\subsection{PCB analysis}

PCBs in PEs were extracted twice by $40 \mathrm{~mL}$ aliquots of hexane for 24 hours each. It was reported that more than $99.9 \%$ of PCBs in PEs could be extracted using this procedure [23]. The PE extracts were passed through a silica gel column to remove organic interferences, concentrated to $1 \mathrm{~mL}$, and analyzed using an Agilent model 6890 gas chromatograph with a DB-5MS capillary column (60 m length and $0.25 \mathrm{~mm}$ I.D.) and a micro electron-capture detector. Details on the PCB analytical procedure are provided elsewhere [23, 25]. The PCB congeners spiked into PEs prior to the experiments, and four sediment-derived PCB congeners, 43 (tetra-), 101 (penta-), 153 (hexa-), and 180 (hepta-chlorinated), were analyzed. Congeners with less than four or more than seven chlorine substituents could not be reliably quantified in the PE extracts. PCB 43 was the only tetra-chlorinated congener that could be reliably quantified. Therefore, one 
representative compound was selected from each PCB homolog group ranging from tetra- to hepta-chlorinated congeners to report unbiased results within the range.

\section{Modeling}

\subsection{Modeling PE exchange kinetics}

Two modeling approaches, first-order and 1-D diffusion, were employed to describe the PCB exchange kinetics for PE in quiescent sediment.

A first-order model is commonly applied to describe HOC exchange kinetics between water and polymeric passive samplers [2, 24, 26]. Tomaszewski and Luthy [7] showed that the results of the model reasonably reproduced PCB uptake data obtained from a field PE deployment. The mathematical expression for the first-order model is given as $[24,26]$

$C_{P E}(t)=C_{P E, e q}\left[1-\exp \left(-k_{e} t\right)\right] \quad$ (uptake kinetics)

$C_{P E}(\mathrm{t})=C_{P E 0} \exp \left(-k_{e} t\right)$ (release kinetics)

where $\mathrm{C}_{\mathrm{PE}}(\mathrm{t})$ and $\mathrm{C}_{\mathrm{PE}, \mathrm{eq}}\left(\mathrm{ng} \mathrm{g}^{-1}\right)$ are the PE concentrations at time $\mathrm{t}(\mathrm{h})$ and equilibrium, respectively; $\mathrm{C}_{\mathrm{PE} 0}\left(\mathrm{ng} \mathrm{g}^{-1}\right)$ is the initial PE concentration; and $\mathrm{k}_{\mathrm{e}}\left(\mathrm{h}^{-1}\right)$ is the first-order exchange rate constant. The first-order exchange rate constant can be further expressed as

$k_{e}=k_{o} /\left(l \cdot K_{P E-w} \cdot d_{P E}\right)$

where $\mathrm{k}_{\mathrm{o}}\left(\mathrm{cm} \mathrm{s}^{-1}\right)$ is the mass transfer coefficient at the interface; $l(\mathrm{~cm})$ is half the PE thickness; $\mathrm{K}_{\mathrm{PE}-\mathrm{w}}\left(\mathrm{cm}^{3}\right.$ water $\left.\mathrm{g} \mathrm{PE}\right)$ is the PE-water partitioning coefficient; and $\mathrm{d}_{\mathrm{PE}}\left(\mathrm{g} \mathrm{cm}^{-3}\right)$ is the PE density. 
A one-dimensional (1-D) diffusion model is frequently used for field passive sampling of HOCs [20, 27]. Details on the concepts and assumptions of the model are described elsewhere [20, 27]. Lampert et al. [20] presented an analytical solution for the 1-D diffusion model when the compound exchange kinetics is governed by the mass transfer on the sediment side (i.e., external resistance):

$$
\begin{aligned}
& \frac{C_{P E}(t)}{C_{P E, e q}}=1-\exp \left(\frac{R D^{\prime} t}{l^{2} K_{P E-w}{ }^{2}}\right) \operatorname{erfc}\left(\frac{\sqrt{R D^{\prime} t}}{l \cdot K_{P E-w}}\right) \quad \text { (uptake kinetics) } \\
& \frac{C_{P E}(t)}{C_{P E 0}}=\exp \left(\frac{R D^{\prime} t}{l^{2} K_{P E-w}{ }^{2}}\right) \operatorname{erfc}\left(\frac{\sqrt{R D^{\prime} t}}{l \cdot K_{P E-w}}\right) \quad \text { (release kinetics) }
\end{aligned}
$$

where $\mathrm{R}$ (dimensionless) is the retardation factor and $D^{\prime}\left(\mathrm{cm}^{2} \mathrm{~s}^{-1}\right)$ is the tortuosity and porosity-corrected diffusion coefficient. The product of $\mathrm{R}$ and $D^{\prime}$, or $\mathrm{R} D^{\prime}$, is treated as a site-specific parameter describing the HOC mass transfer at the sediment side [20].

The validity of the external resistance assumption was examined by calculating the ratio of characteristic times for internal (i.e., within a passive sampler) and external (i.e., within sediment matrix) diffusion [20]

$\frac{t_{\text {external }}}{t_{\text {internal }}}=\frac{36.1 K_{P E-w}^{2} D_{P E}}{R D^{\prime}}=36.1 \sigma$

where $D_{P E}\left(\mathrm{~cm}^{2} \mathrm{~s}^{-1}\right)$ is the diffusivity within PE. A regression model to obtain the $\mathrm{D}_{\mathrm{PE}}$ values for HOCs using molar volumes was given by Lohmann [28]. When the parameter $\sigma$ is greater than unity, external resistance can be safely assumed at any time $\mathrm{t}$ [20]. This was undoubtedly true for the study sediment and PCBs, which gives $\sigma$ values in the range of $3 \times 10^{5}$ to $7 \times 10^{7}$. 


\subsection{Estimating $C_{\text {free }}$ using non-equilibrium PE sampling methods}

The freely dissolved concentrations $\left(\mathrm{C}_{\text {free }}\right)$ of the sediment-derived PCBs, congeners 43 , 101, 153, and 180, were determined using two non-equilibrium PE sampling methods, a PRC-based method and a novel method using multiple PE thicknesses. From the sediment microcosm experiments, $\mathrm{C}_{\text {free }}$ was determined for each contact time and for each PE thickness for the PRC method, and for each contact time using PE uptake data for all three PE thicknesses for the multiple PE thickness method. When the two methods are applied for non-equilibrium passive sampling of $\mathrm{C}_{\text {free}}, \mathrm{PE}$ with a single thickness is exposed to sediment for a certain period of time for the PRC method, and PE with multiple thicknesses will be installed close to one another and exposed for a certain period of time for the multiple PE thickness method.

The PRC method was applied following a procedure described in Lampert et al. [20]. PCB congeners 29, 69, 103, 155, and 192 were used as PRCs. From PE concentration for each of the PRCs at a certain exposure time with a certain PE thickness, the values of $R D^{\prime}$ could be obtained using eq. (5). The logarithms of the $R D^{\prime}$ values were plotted against the $\log \mathrm{K}_{\mathrm{ow}}$ values of the PRCs to find a linear correlation:

$\log \left(R D^{\prime}\right)=\alpha \cdot \log K_{o w}+b$

Use of the $R D^{\prime}$ values was limited to the case when the PE concentration for a PRC is statistically significantly lower than the initial concentration at a confidence interval of $99 \%$. Using the linear relationship between $\mathrm{K}_{\mathrm{ow}}$ and $R D^{\prime}$, the $R D^{\prime}$ value for a target analyte was estimated. Extrapolation was not allowed, in other words, the $R D^{\prime}$ value for a target analyte was obtained only when its $\mathrm{K}_{\mathrm{ow}}$ was within the range of $\mathrm{K}_{\mathrm{ow}}$ values for 
PRCs used to obtain $\alpha$ and $\beta$. Finally, the freely dissolved aqueous concentration, $\mathrm{C}_{\text {free, }}$, for a target analyte was calculated by:

$C_{f r e e}=\frac{C_{P E}(t)}{K_{P E-w}} \cdot\left[1-\exp \left(\frac{R D^{\prime} t}{l^{2} K_{P E-w}^{2}}\right) \operatorname{erfc}\left(\frac{\sqrt{R D^{\prime} t}}{l \cdot K_{P E-w}}\right)\right]^{-1}$

As long as the conditions above were met, $\mathrm{C}_{\text {free }}$ was calculated for PE with each thickness at each exposure time. This allowed the validation of the PRC method with a large set of data.

A novel non-equilibrium PE sampling method using multiple PE thicknesses was developed and used as follows. When a certain type of PE sampler, $i$, is exposed to sediment for time $t$, the PE concentration is expressed as

$C_{P E, i}(t)=K_{P E-w, i} \cdot C_{\text {free }} \cdot\left[1-\exp \left(\frac{R D^{\prime} t}{l_{i}^{2} K_{P E-w, i}{ }^{2}}\right) \operatorname{erfc}\left(\frac{\sqrt{R D^{\prime} t}}{l_{i} \cdot K_{P E-w, i}}\right)\right]$

If $\mathrm{C}_{\mathrm{PE}, \mathrm{i}}(\mathrm{t})$ is obtained for $\mathrm{PE}$ with two or more thicknesses, the data can be used to estimate both $R D^{\prime}$ and $C_{\text {free }}$ values as there are two or more equations with two unknowns. A nonlinear least-squares method was employed to calculate the values of $\mathrm{R} D^{\prime}$ and $\mathrm{C}_{\text {free }}$ from eq. (9) using the experimental data. The $\mathrm{C}_{\text {free }}$ was not obtained when the PE thickness ratios (i.e., $\theta_{i} / \theta_{j}$; $\theta=$ sampler thickness) were within the $99 \%$ confidence intervals for the reciprocals of concentration ratios (i.e., $\left.\left[\mathrm{C}_{\mathrm{PE}, \mathrm{i}}(\mathrm{t}) / \mathrm{C}_{\mathrm{PE}, \mathrm{j}}(\mathrm{t})\right]^{-1}\right)$. When the two values are identical, an array of eq. (9) for multiple PE thicknesses gives a trivial solution.

\section{Results and Discussion}

\subsection{Partitioning coefficients for different types of PES}


Concentrations of PCB congeners 29, 69, 103, 155, and 192 in PEs equilibrated in the same batch of 80/20 (v/v) methanol/water solution are slightly different from each other for PEs with different thicknesses and from different manufacturers (Fig. A.1 in the Supplementary Data). Variations in equilibrium concentrations among different types of PEs are also found for congeners 43, 101, 153, and 180 in the slurry phase PE-sediment equilibrium experiments (Fig. A.2 in the Supplementary Data). The equilibrium PE concentrations are higher for 51 and $102 \mu \mathrm{m}$ Husky PEs, and lower for $17 \mu \mathrm{m}$ Husky PE than $51 \mu \mathrm{m}$ Brentwood PE (Two-way ANOVA, $p<0.05$ ). The differences in concentrations between 51 and $102 \mu \mathrm{m}$ Husky PEs are not statistically significant (Twoway ANOVA, $p>0.1)$. These results indicate the PEs with different thicknesses and from different manufacturers have slightly different affinity to PCBs presumably because of the difference in the additives applied or in the plastic structure. Because of the variation in PCB affinities, the PCB PE-water partitioning coefficients $\left(\mathrm{K}_{\mathrm{PE}-\mathrm{w}}\right)$ should be different for the different types of PEs. Using the experimentally determined $\mathrm{K}_{\mathrm{PE}-\mathrm{w}} \mathrm{S}$ for $51 \mu \mathrm{m}$ Brentwood PE available in Choi et al. [23] and the ratio of equilibrium concentrations for different types of PEs, the $\mathrm{K}_{\mathrm{PE}-\mathrm{w}}$ values for 17, 51, and $102 \mu \mathrm{m}$ Husky PEs are determined for the study congeners. The $\mathrm{K}_{\mathrm{PE}-\mathrm{w}}$ values calculated for the Husky PEs at salinities of 0 and $30 \mathrm{~g} \mathrm{~L}^{-1}$ are listed in Table A.1 in the Supplementary Data. The $\mathrm{K}_{\mathrm{PE}-\mathrm{w}}$ values determined in this study are within or close to the range of the values reported in the literature as shown in Table A.2 in the Supplementary Data.

\subsection{Sediment PCB uptake kinetics in a quiescent system}


The PCB uptake kinetics for congeners 43 (tetra-), 101 (penta-), 153 (hexa-), and 180 (hepta-chlorinated) in quiescent sediment is shown in Fig. 1. As expected, the uptake kinetics is distinctly faster for the thinner PE. To compare the uptake kinetics for PE with different thicknesses, the ratios of the $\mathrm{C}_{\mathrm{PE}}(\mathrm{t})$ values for 51 and $102 \mu \mathrm{m}$ PE to the values for $17 \mu \mathrm{m}$ PE are presented in Table 1. The data show that for relatively short contact times, the PE concentrations are nearly inversely proportional to PE thickness. For example, the $\mathrm{C}_{\mathrm{PE}}(\mathrm{t})_{51 \mu \mathrm{m}} / \mathrm{C}_{\mathrm{PE}}(\mathrm{t})_{17 \mu \mathrm{m}}$ values are in the range of 0.30-0.36 (thickness ratio: 3.0) and the $\mathrm{C}_{\mathrm{PE}}(\mathrm{t})_{102 \mu \mathrm{m}} / \mathrm{C}_{\mathrm{PE}}(\mathrm{t})_{17 \mu \mathrm{m}}$ values in the range of 0.16-0.19 (thickness ratio: 6.0 ) for congener 180 at contact times equal to or less than 64 days. In other words, it is seen that the PCB mass accumulated in PE is not a function of sampler thickness at the early phase of exposure. This is because the PCB flux at the PE-sediment boundary is not affected by the concentration in the PE since it is effectively close to zero compared to the equilibrium concentration at relatively short exposure times.

With increase in contact time, the $\mathrm{C}_{\mathrm{PE}}(\mathrm{t})_{51 \mu \mathrm{m}} / \mathrm{C}_{\mathrm{PE}}(\mathrm{t})_{17 \mu \mathrm{m}}$ and $\mathrm{C}_{\mathrm{PE}}(\mathrm{t})_{102 \mu \mathrm{m}} / \mathrm{C}_{\mathrm{PE}}(\mathrm{t})_{17 \mu \mathrm{m}}$ values become larger and significantly deviate from $1 / 3$ and $1 / 6$, respectively. For example, for PCB 43 with a contact time of 132 days, the $\mathrm{C}_{\mathrm{PE}}(\mathrm{t})_{51 \mu \mathrm{m}} / \mathrm{C}_{\mathrm{PE}}(\mathrm{t})_{17 \mu \mathrm{m}}$ and $\mathrm{C}_{\mathrm{PE}}(\mathrm{t})_{102 \mu \mathrm{m}} / \mathrm{C}_{\mathrm{PE}}(\mathrm{t})_{17 \mu \mathrm{m}}$ values are 0.62 and 0.48 , respectively. As the thinner PE approaches faster towards equilibrium, the PCB flux at the PE-sediment boundary is reduced more rapidly for the thinner $\mathrm{PE}$. The $\mathrm{PE}$ concentrations relative to the equilibrium $\mathrm{PE}$ concentrations $\left(\mathrm{C}_{\mathrm{PE}}(\mathrm{t}) / \mathrm{C}_{\mathrm{PE} \text {,eq }}\right)$ for $\mathrm{PCB} 43$ at 132 days are $0.39,0.20$, and 0.15 for 17,51 , and $102 \mu \mathrm{m}$ PE, respectively. 
Table 1. The ratio of PE concentrations for $51 \mu \mathrm{m}$ and $17 \mu \mathrm{m}$ PEs $\left(\mathrm{C}_{\mathrm{PE}}(\mathrm{t})_{51 \mu \mathrm{m}} / \mathrm{C}_{\mathrm{PE}}(\mathrm{t})_{17 \mu \mathrm{m}}\right)$ and for $102 \mu \mathrm{m}$ and $17 \mu \mathrm{m}$ PEs $\left(\mathrm{C}_{\mathrm{PE}}(\mathrm{t})_{102}\right.$ $\left.{ }_{\mu \mathrm{m}} / \mathrm{C}_{\mathrm{PE}}(\mathrm{t})_{17 \mu \mathrm{m}}\right)$ for the PCB uptake kinetics experiment in sediment microcosms. The values are shown as mean \pm standard deviation.

\begin{tabular}{|c|c|c|c|c|c|c|c|c|}
\hline \multirow{2}{*}{$\begin{array}{l}\text { Contact } \\
\text { time (d) }\end{array}$} & \multicolumn{4}{|c|}{$\mathrm{C}_{\mathrm{PE}}(\mathrm{t})_{51 \mu \mathrm{m}} / \mathrm{C}_{\mathrm{PE}}(\mathrm{t})_{17 \mu \mathrm{m}}$} & \multicolumn{4}{|c|}{$\mathrm{C}_{\mathrm{PE}}(\mathrm{t})_{102 \mu \mathrm{m}} / \mathrm{C}_{\mathrm{PE}}(\mathrm{t})_{17 \mu \mathrm{m}}$} \\
\hline & PCB 43 & PCB 101 & PCB 153 & PCB 180 & PCB 43 & PCB 101 & PCB 153 & PCB 180 \\
\hline 1 & $0.36 \pm 0.08$ & $0.34 \pm 0.07$ & $0.36 \pm 0.07$ & $0.33 \pm 0.09$ & $0.19 \pm 0.04$ & $0.18 \pm 0.04$ & $0.21 \pm 0.04$ & $0.17 \pm 0.04$ \\
\hline 4 & $0.40 \pm 0.03$ & $0.42 \pm 0.03$ & $0.38 \pm 0.03$ & $0.36 \pm 0.04$ & $0.23 \pm 0.02$ & $0.20 \pm 0.03$ & $0.20 \pm 0.03$ & $0.17 \pm 0.02$ \\
\hline 16 & $0.38 \pm 0.02$ & $0.33 \pm 0.02$ & $0.36 \pm 0.12$ & $0.30 \pm 0.02$ & $0.22 \pm 0.01$ & $0.19 \pm 0.01$ & $0.20 \pm 0.07$ & $0.16 \pm 0.02$ \\
\hline 64 & $0.55 \pm 0.14$ & $0.41 \pm 0.05$ & $0.36 \pm 0.04$ & $0.35 \pm 0.03$ & $0.30 \pm 0.02$ & $0.22 \pm 0.01$ & $0.19 \pm 0.01$ & $0.19 \pm 0.01$ \\
\hline 132 & $0.62 \pm 0.06$ & $0.48 \pm 0.04$ & $0.40 \pm 0.03$ & $0.37 \pm 0.02$ & $0.48 \pm 0.07$ & $0.33 \pm 0.04$ & $0.27 \pm 0.04$ & $0.25 \pm 0.04$ \\
\hline 264 & $0.64 \pm 0.10$ & $0.44 \pm 0.05$ & $0.36 \pm 0.03$ & $0.33 \pm 0.03$ & $0.44 \pm 0.09$ & $0.29 \pm 0.04$ & $0.21 \pm 0.04$ & $0.18 \pm 0.02$ \\
\hline
\end{tabular}


(a) $1^{\text {st }}$ order model
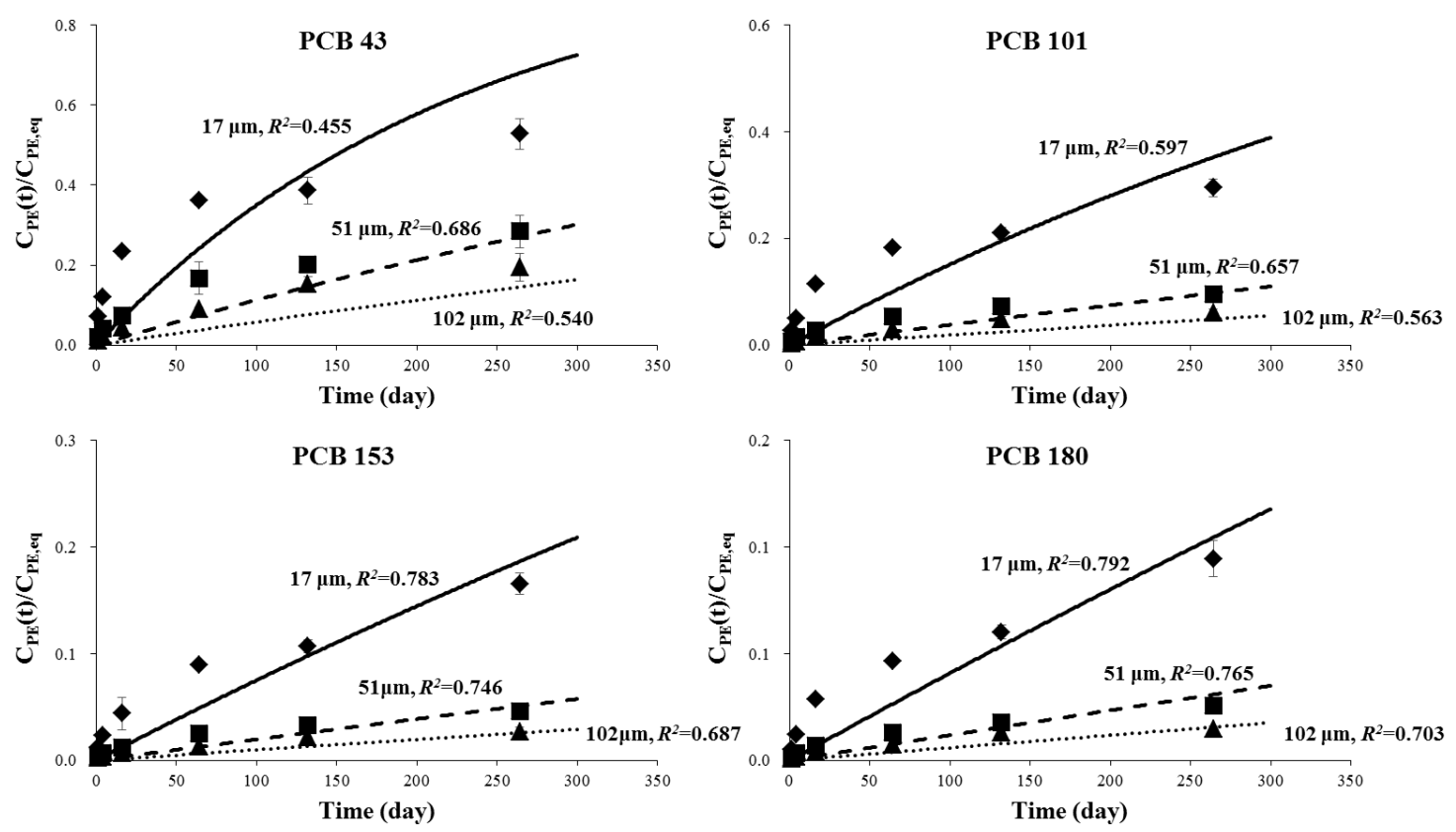

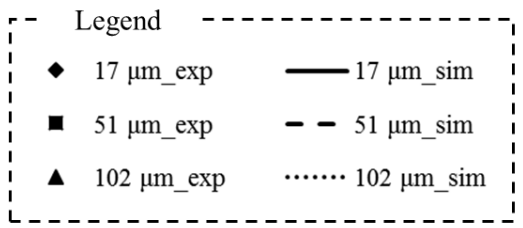


(b) 1-D diffusion model with external resistance
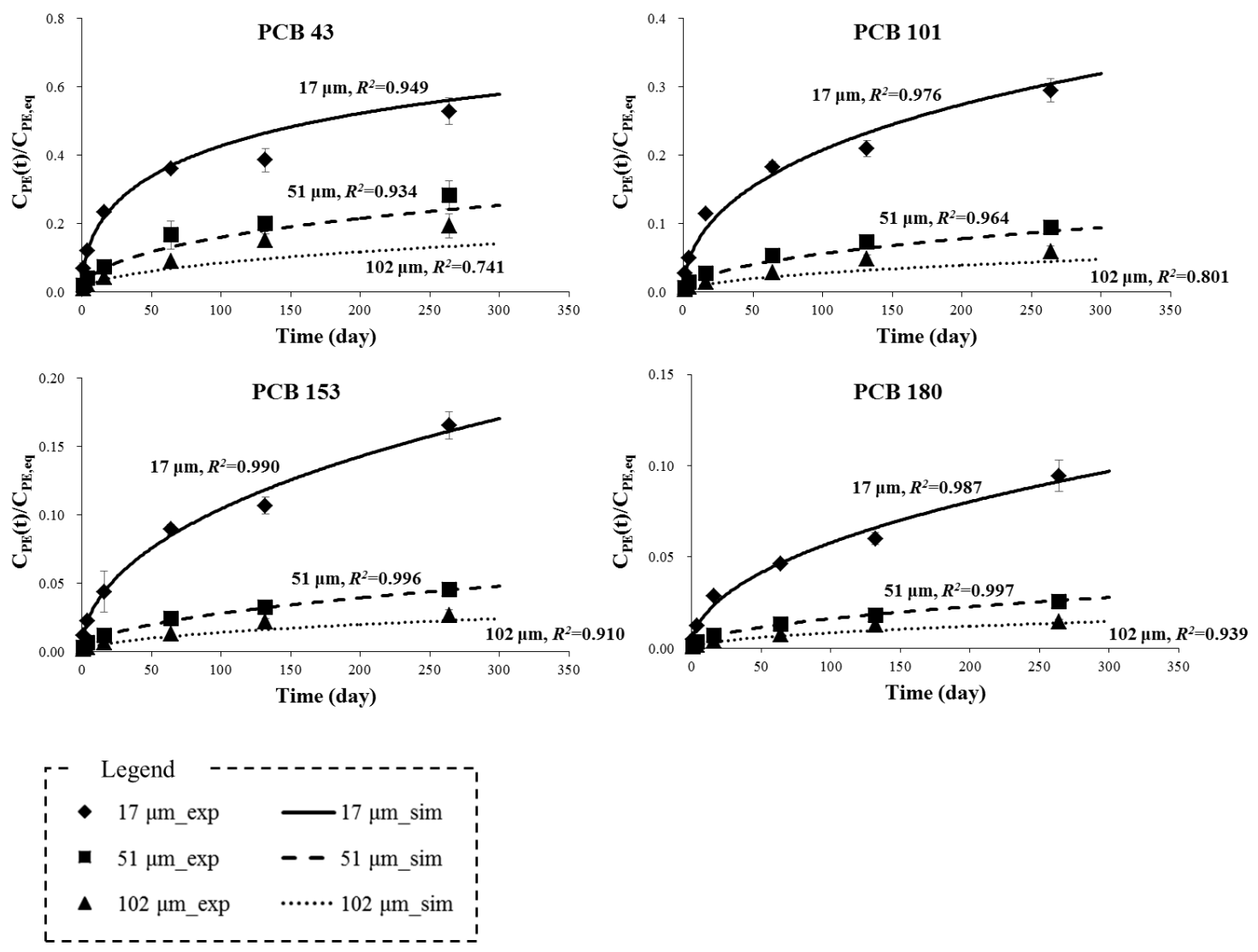

Fig. 1. Comparison of experimental data and simulation results using (a) $1^{\text {st }}$ order model and (b) 1-D diffusion model with external resistance for PCB uptake kinetics of PE in quiescent sediment. The values are shown as the PE concentration at each contact time relative to the equilibrium PE concentration determined in the slurry phase experiments $\left(\mathrm{C}_{\mathrm{PE}}(\mathrm{t}) / \mathrm{C}_{\mathrm{PE}, \mathrm{eq}}\right)$. The experimental data are shown as means (symbols) with standard deviations (bars). 


\subsection{Comparison of experimental and modeling results}

The first-order kinetic model does not appropriately predict the PE uptake kinetics in quiescent sediment. The lines in Fig. 1a represent the simulation results using the firstorder kinetics with an exchange rate constant fitted with the experimental data for all PE thicknesses for each PCB congener. The experimental data show curvilinear PCB uptake pattern at the earlier phase of the experiment (see Fig.A.3 in the Supplementary Data for expansion of the earlier phase). This PCB uptake pattern cannot be reproduced by the first-order model which generates an almost linear uptake kinetics for small $\mathrm{C}_{\mathrm{PE}}(\mathrm{t}) / \mathrm{C}_{\mathrm{PE} \text {,eq }}$ values (e.g., less than 0.3). Previous studies demonstrated that the curvilinear HOC uptake occurs when HOCs near the passive sampler surface are continuously depleted [7, 29]. The significant deviation of the measured data from the first-order kinetic model suggests that a significant depletion of PCBs near the PE surface occurs at the earlier phase of PE-sediment contact in the current study.

On the other hand, the 1-D diffusion model with external resistance reasonably fit with the experimental data for all PE thicknesses (Fig. 1b). The $\mathrm{R}^{2}$ values are greater than 0.90 for all cases except for $102 \mu \mathrm{m}$ PE for PCB $43\left(\mathrm{R}^{2}=0.741\right)$ and PCB $101\left(\mathrm{R}^{2}=0.801\right)$. The curvilinear PCB uptake pattern in the earlier phase of contact is well reproduced by the 1-D diffusion model (see Fig.A.4 in the Supplementary Data for expansion of the earlier phase).

The PE release kinetics for congeners 29, 69, 103, 155, and 192 are plotted in Fig. 2. The data show that the PE release kinetics is distinctly faster for the less chlorinated and for thinner PEs. For relatively highly chlorinated congeners, little changes in PE 
concentrations are observed even after a long contact time. For example, only $20 \%$ and $11 \%$ reduction in PE concentrations are observed compared to the initially spiked amounts for 17 and $102 \mu \mathrm{m}$ PE, respectively, for PCB 192 after 264 days of contact ( $p=0.004$ and 0.035 for 17 and $102 \mu \mathrm{m}$ PE, respectively, Student's t-test). These results are comparable to those by Apell and Gschwend [10] showing 25\% reduction in PE concentration for PCB 178 (hepta-chlorinated) after 120 days of contact in a quiescent sediment bed using $25 \mu \mathrm{m}$ PE. Note that the overall standard error among the replicates in this study is $2.6 \%$ of the mean values. This suggests that, even with a rigorous analytical technique, contact times on the order of months are required to observe statistically significant reduction of initially spiked PE concentrations for highly chlorinated PCB congeners.

The 1-D diffusion model with external resistance gives a reasonable prediction of the experimental data for any PE thicknesses and for any congeners. In all cases, the modeling results are within $15 \%$ of the experimentally measured data. 

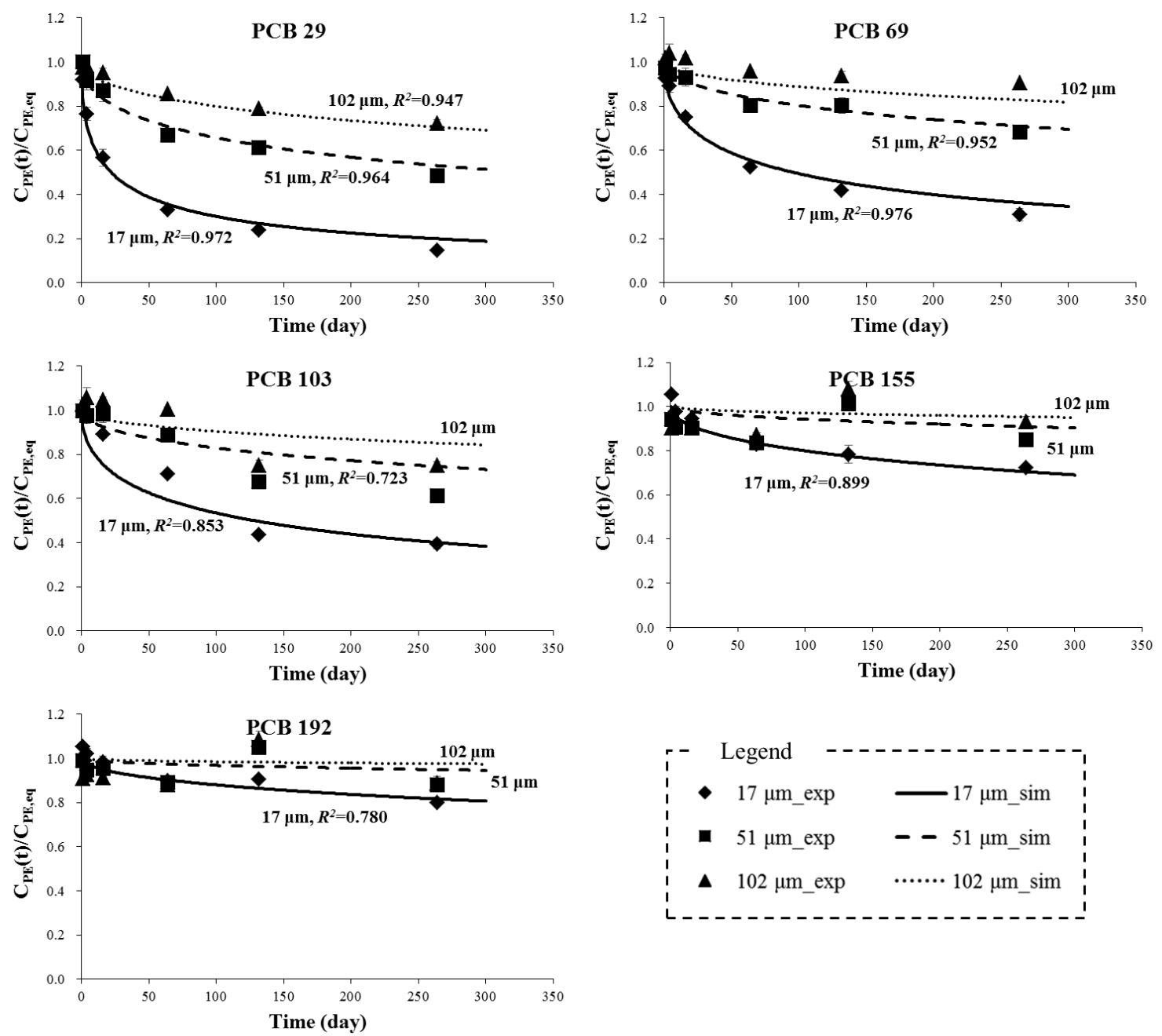

Fig. 2. Comparison of experimental data and simulation results using 1-D diffusion model with external resistance for PCB release kinetics of PE in quiescent sediment. The values are shown as the PE concentration at each contact time relative to the initial PE concentration $\left(\mathrm{C}_{\mathrm{PE}}(\mathrm{t}) / \mathrm{C}_{\mathrm{PE}}(0)\right)$. The experimental data are shown as means (symbols) with standard deviations (bars). The $R^{2}$ values are presented only for the cases when statistically significant reductions in PE concentration are observed at a confidence level of $99 \%$ for more than two contact times.

\subsection{Anisotropic PCB exchange kinetics}


The logarithms of the best-fit values of $\mathrm{R} D^{\prime}$ for PE uptake and release kinetics are plotted against the logarithms of octanol-water partitioning coefficients ( $\log \mathrm{K}_{\mathrm{ow}}$ ) of PCB congeners in Fig. 3. The $\log \mathrm{R} D^{\prime}$ values for different PCB congeners show correlation with the $\log \mathrm{K}_{\mathrm{ow}}$ values for either PE uptake or release kinetics. This is in line with the study by Lampert et al. [20] who reported a linear correlation between the $\log \mathrm{R} D^{\prime}$ and the $\log \mathrm{K}_{\mathrm{ow}}$ for uptake kinetics of PAHs to PDMS fiber.

More importantly, the correlation between the $\log \mathrm{R} D^{\prime}$ and $\log \mathrm{K}_{\mathrm{ow}}$ indicates potential anisotropic PCB exchange kinetics for PE. Fig. 3 shows that the $\mathrm{R} D^{\prime}$ values are distinctly greater for release kinetics than for uptake kinetics. From the regression curves, it is estimated that the $\mathrm{R} D^{\prime}$ values are 0.5 to $0.6 \log$ units greater for release kinetics than for uptake kinetics with the same $\mathrm{K}_{\text {ow }}$. The best-fit value and $95 \%$ confidence intervals of $\mathrm{R} D^{\prime}$ for uptake kinetics for four PCB congeners are well below the regression line for release kinetics. The $95 \%$ confidence intervals of $\mathrm{R} D^{\prime}$ obtained for release kinetics overlap with the regression line for PE uptake kinetics for only one (PCB 192) of the five PCB congeners analyzed. As discussed in the previous section, for PCB 192, there is only small difference (equal or less than 20\%) between the initially spiked amount and the residual amount in PE after exposure. Therefore, analytical errors cause a wide confidence interval for the estimated $\mathrm{R} D^{\prime}$ value for this congener. 


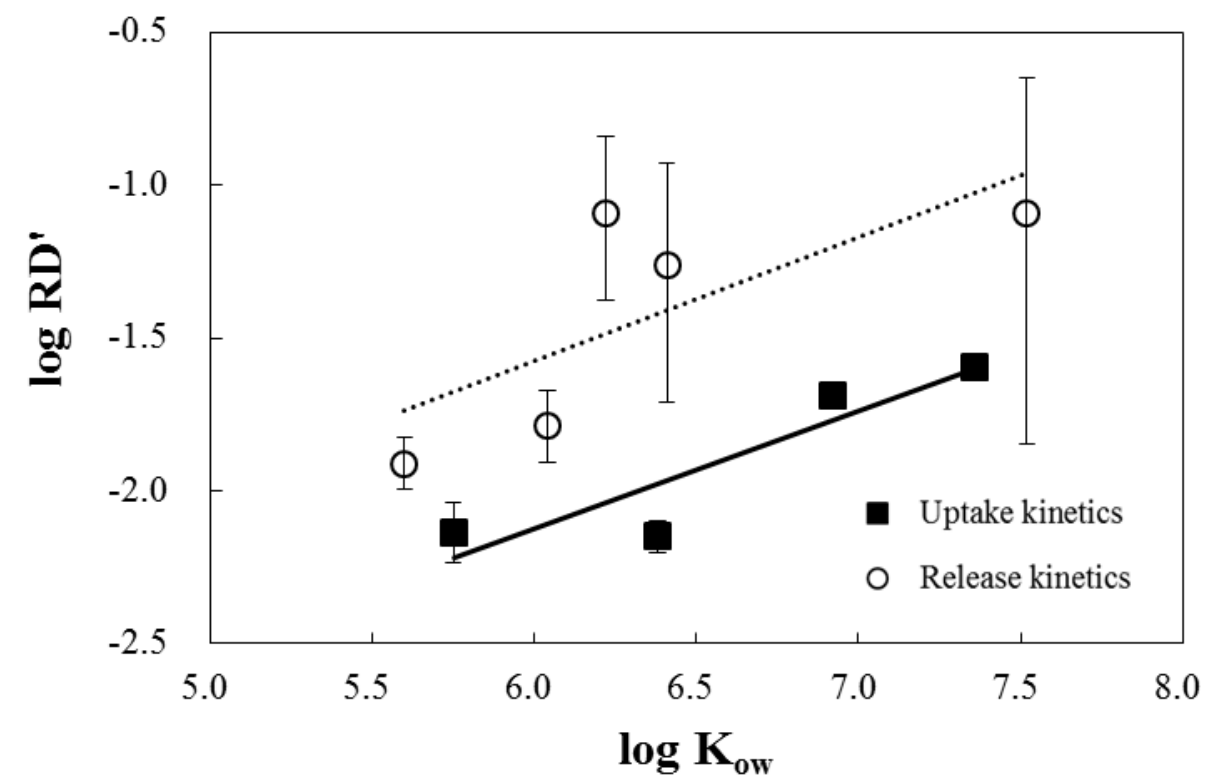

Figure 3. Correlation of the $\mathrm{RD}^{\prime}$ values obtained for $\mathrm{PE}$ uptake and release kinetics with the octanol-water partitioning coefficients $\left(\mathrm{K}_{\mathrm{ow}}\right)$. The symbols represent the best-fit $\mathrm{RD}^{\prime}$ values, the error bars $95 \%$ confidence intervals, and the lines the linear regression curves.

Assuming that the PE exchange kinetics is fully governed by external mass transfer, the anisotropic PE exchange kinetics should be a result of different PCB mass transfer kinetics within sediment in two directions, from sediment to the vicinity of PE and from the vicinity of PE to sediment. Thus, a plausible explanation for the anisotropic exchange kinetics observed in the current study is that there is sorption-desorption hysteresis due to aging and sequestration of PCBs present in the sediment. The study sediment collected from Hunters Point Shipyard, CA, USA has been contaminated with PCBs for decades [30]. The total amount of PCBs desorbable within 30 days was reported to be $37 \%$ and $35 \%$ for congeners 153 and 180, respectively, indicating relatively slow PCB desorption kinetics from sediment [31]. The aging and sequestration 
of the legacy contaminants in sediment may have resulted in sorption-desorption hysteresis, which, in turn, results in anisotropic exchange kinetics for PE in contact with the sediment.

It should be noted that a recent study by Bao et al. [11] reported results exactly opposite to those of the current study. Bao et al. [11] showed that the target analyte uptake rates were faster than the PRC release rates for PDMS fibers contacted to a sediment spiked with DDTs and PCBs in the laboratory. These authors proposed the low chemical potential between the PDMS fiber and sediment pore-water as a mechanism that retarded the release of PRCs from the fiber [11]. Combining the observations in Bao et al. [11] and the current study, it is likely that the PRC release rates can be either slower or faster than the target analyte uptake rates, presumably depending on the physicochemical properties of sediment and compounds, sediment aging, and sampler types. Further studies under controlled laboratory conditions are needed to verify the mechanisms involved in the anisotropic exchange kinetics and the relative significance of each mechanism at different conditions.

\subsection{Determination of $C_{\text {free }}$ using non-equilibrium PE sampling methods}

The freely dissolved concentrations, $\mathrm{C}_{\text {free}}$, estimated by the two non-equilibrium $\mathrm{PE}$ sampling methods are compared to the $\mathrm{C}_{\text {free }}$ obtained by equilibrium PE sampling in the slurry phase experiment in Fig. 4. The $\mathrm{C}_{\text {free }}$ estimated by both methods are all within $\pm 0.3 \log$ units of the $C_{\text {free }}$ obtained by equilibrium sampling (i.e., less than a factor of two difference) except for one case. The $\mathrm{C}_{\text {free }}$ for PCB 101 estimated by the multiple PE 
thickness model using PE measurement results for an exposure time of 132 days is smaller than the $\mathrm{C}_{\text {free }}$ value determined by equilibrium sampling by $0.41 \log$ unit.

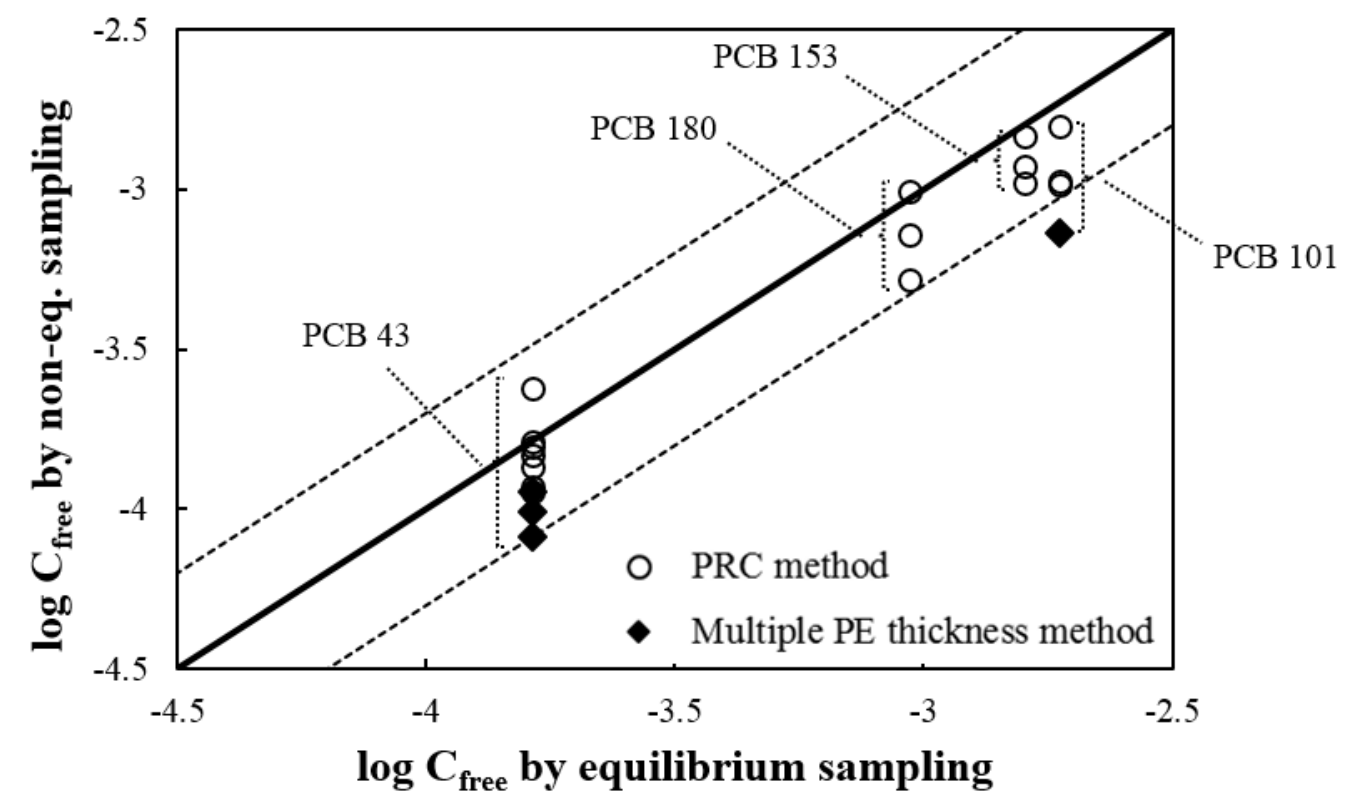

Figure 4. Comparison of the freely dissolved concentrations $\left(\mathrm{C}_{\text {free }}\right)$ determined using the non-equilibrium sampling methods and that determined by equilibrium sampling in a sediment slurry. The solid line represents identical $\mathrm{C}_{\text {free }}$ and the dashed lines represent $\pm 0.3 \log$ unit difference. Results for PCB 153 and 180 could not be obtained for the multiple PE thickness method for the exposure times applied in the current study.

The PRC method slightly underestimates $\mathrm{C}_{\text {free }}$ for PCB 101, 153, and 180 because of the relatively faster PRC release rates than the analyte uptake rates. However, the anisotropic exchange kinetics does not result in serious deviation of the PRC-based $\mathrm{C}_{\text {free }}$ estimation from the equilibrium sampling results. The $\mathrm{C}_{\text {free }}$ obtained by the PRC method is not highly sensitive to the $\mathrm{R} D^{\prime}$ value as discussed in Text A.1 along with a result of error analysis shown in Table A.3 in the Supplementary Data. For the PRC-based 
calculations in this study, the variation of $\mathrm{R} D^{\prime}$ by $0.5 \log$ units results in less than $50 \%$ difference in the estimated $\mathrm{C}_{\text {free }}$.

Overall, despite the anisotropy of PE exchange kinetics observed, the PRC method shows slightly better accuracy than the multiple PE thickness method. The multiple PE thickness method is relatively sensitive to the difference between the model and the actual measurement, which results from analytical error and/or the deviation of the actual PE exchange kinetics from the model assumptions. For PCB 43 as an example, it is seen from Fig. 1b that the modeling results somewhat underestimate the uptakes for 51 and $102 \mu \mathrm{m}$ PE while overestimating the uptakes for $17 \mu \mathrm{m}$ PE. In this situation, the multiple PE thickness method should underestimate the $\mathrm{C}_{\text {free }}$. The errors associated with the multiple PE thickness method are discussed in Text A.2 along with the analysis results in Table A.4 and A.5 in the Supplementary Data. It is shown that $\pm 15 \%$ difference between the model and the actual measurement of PE concentration results in a maximum of $0.42 \log$ unit error in the estimated $\mathrm{C}_{\text {free }}$ value using the multiple PE thickness method. Another significant source of error for the multiple PE thickness method is the uncertainty in $\mathrm{K}_{\mathrm{PE}-\mathrm{w}}$ determination. Variation of $\mathrm{K}_{\mathrm{PE}-\mathrm{w}}$ by $15 \%$ results in a maximum of $0.31 \log$ unit variation in calculated $\mathrm{C}_{\text {free. }}$.

Using the multiple PE thickness method, $\mathrm{C}_{\text {free }}$ is calculated for cases with PCB 43 at exposure times of 64, 132, and 264 days, and PCB 101 at an exposure time of 132 days. For other cases, the method is not applicable because the reciprocals of concentration ratios do not significantly deviate from the PE thickness ratios. This suggests that the method has limited applicability for highly chlorinated PCB congeners. 
Still, the results show the potential of the multiple PE thickness method to estimate the freely dissolved $\mathrm{HOC}$ concentrations. The $\mathrm{C}_{\text {free }}$ values estimated using the multiple PE thickness method are within 39-69\% of the equilibrium sampling results (i.e., less than a factor of three difference). Supposing that the discussions in the current paper are valid, the method may have advantage over the PRC method for moderately hydrophobic compounds (e.g., PCBs with relatively small number of chlorine substituents and PAHs) that have undergone significant aging in sediments. Studies applying the multiple PE thickness method in these situations are needed to further validate its performance.

\section{Conclusions}

This study demonstrated the anisotropy of PCB uptake into and release from PE passive samplers installed in quiescent sediment. The kinetic parameter describing the PCB transport within sediment, the $\mathrm{R} D^{\prime}$ value, was determined to be 0.5 to $0.6 \log$ units greater for uptake of PCBs into PE compared to release from PE, which indicated faster uptake kinetics than release.

A novel non-equilibrium passive sampling method employing multiple PE thicknesses was developed and used to predict PCB $\mathrm{C}_{\text {free }}$ in sediment pore-water from sediment microcosms. The new method showed a reasonable performance, estimating PCB $\mathrm{C}_{\text {free }}$ within a factor of three of the value determined by equilibrium PE sampling. For the study sediment, however, the multiple PE thickness method was shown not to be superior to the previously developed PRC method. The validity of the newly developed multiple PE thickness method and the PRC method for non-equilibrium passive sampling 
of sediment pore-water HOCs needs to be further studied using sediment and HOCs with different characteristics.

\section{Acknowledgements}

Funding for this research was provided by the Department of Defense Strategic

Environmental Research and Development Program (SERDP; ER-1552 Phase III), and

Basic Science Research Program through the National Research Foundation of Korea

(NRF) funded by the Ministry of Science, ICT \& Future Planning

(2015R2C1A1A02036713). Yongju Choi would like to thank the Institute of

Construction and Environmental Engineering (ICEE) at Seoul National University for technical support. 


\section{REFERENCES}

[1] U. Ghosh, S. Kane Driscoll, R.M. Burgess, M.T. Jonker, D. Reible, F. Gobas, Y. Choi, S.E. Apitz, K.A. Maruya, W.R. Gala, M. Mortimer, C. Beegan, Passive sampling methods for contaminated sediments: practical guidance for selection, calibration, and implementation, Integr Environ Assess Manag, 10 (2014) 210-223.

[2] R.G. Adams, R. Lohmann, L.A. Fernandez, J.K. MacFarlane, P.M. Gschwend, Polyethylene devices: passive samplers for measuring dissolved hydrophobic organic compounds in aquatic environments, Environ. Sci. Technol., 41 (2007) 1317-1323.

[3] S.B. Hawthorne, M.T. Jonker, S.A. van der Heijden, C.B. Grabanski, N.A. Azzolina, D.J. Miller, Measuring picogram per liter concentrations of freely dissolved parent and alkyl PAHs (PAH-34), using passive sampling with polyoxymethylene, Anal. Chem., 83 (2011) 6754-6761.

[4] S.B. Hawthorne, D.J. Miller, C.B. Grabanski, Measuring low picogram per liter concentrations of freely dissolved polychlorinated biphenyls in sediment pore water using passive sampling with polyoxymethylene, Anal. Chem., 81 (2009) 9472-9480.

[5] T.L. ter Laak, F.J. Busser, J.L. Hermens, Poly(dimethylsiloxane) as passive sampler material for hydrophobic chemicals: effect of chemical properties and sampler characteristics on partitioning and equilibration times, Anal. Chem., 80 (2008) 3859-3866.

[6] R.G. Adams, Polyethylene devices and the effects of sediment resuspension on the cycling of PAHs and PCBs in the lower Hudson Estuary, in: Department of Civil and 
Environmental Engineering, Massachusetts Institute of Technology, Cambridge, MA, 2002.

[7] J.E. Tomaszewski, R.G. Luthy, Field deployment of polyethylene devices to measure PCB concentrations in pore water of contaminated sediment, Environ. Sci. Technol., 42 (2008) 6086-6091.

[8] P. Mayer, T.F. Parkerton, R.G. Adams, J.G. Cargill, J. Gan, T. Gouin, P.M. Gschwend, S.B. Hawthorne, P. Helm, G. Witt, J. You, B.I. Escher, Passive sampling methods for contaminated sediments: scientific rationale supporting use of freely dissolved concentrations, Integr. Environ. Assess. Manag., 10 (2014) 197-209.

[9] K. Booij, F. Smedes, An improved method for estimating in situ sampling rates of nonpolar passive samplers, Environ. Sci. Technol., 44 (2010) 6789-6794.

[10] J.N. Apell, P.M. Gschwend, Validating the Use of Performance Reference Compounds in Passive Samplers to Assess Porewater Concentrations in Sediment Beds, Environ. Sci. Technol., 48 (2014) 10301-10307.

[11] L.-J. Bao, X. Wu, F. Jia, E.Y. Zeng, J. Gan, Isotropic exchange on SPME fiber in sediment under stagnant conditions: implications for field application of PRC calibration, Environ. Toxicol. Chem., Accepted (2016).

[12] G. Witt, S.C. Lang, D. Ullmann, G. Schaffrath, D. Schulz-Bull, P. Mayer, Passive equilibrium sampler for in situ measurements of freely dissolved concentrations of hydrophobic organic chemicals in sediments, Environ. Sci. Technol., 47 (2013) 78307839. 
[13] S. Schafer, C. Antoni, C. Mohlenkamp, E. Claus, G. Reifferscheid, P. Heininger, P. Mayer, Equilibrium sampling of polychlorinated biphenyls in River Elbe sediments-Linking bioaccumulation in fish to sediment contamination, Chemosphere, 138 (2015) 856-862.

[14] K. Maaenpaa, M.T. Leppanen, F. Reichenberg, K. Figueiredo, P. Mayer, Equilibrium sampling of persistent and bioaccumulative compounds in soil and sediment: comparison of two approaches to determine equilibrium partitioning concentrations in lipids, Environ. Sci. Technol., 45 (2011) 1041-1047.

[15] F. Reichenberg, F. Smedes, J.A. Jonsson, P. Mayer, Determining the chemical activity of hydrophobic organic compounds in soil using polymer coated vials, Chem. Cent. J., 2 (2008) 8.

[16] A. Jahnke, P. Mayer, M.S. McLachlan, Sensitive equilibrium sampling to study polychlorinated biphenyl disposition in Baltic Sea sediment, Environ. Sci. Technol., 46 (2012) 10114-10122.

[17] T. Komarova, M.E. Bartkow, J.F. Muller, S. Carter, J. Vanderzalm, Field evaluation of passive samplers: Monitoring polycyclic aromatic hydrocarbons (PAHs) in stormwater, Polycycl. Aromat. Comp., 26 (2006) 221-236.

[18] A. Jahnke, M.S. McLachlan, P. Mayer, Equilibrium sampling: partitioning of organochlorine compounds from lipids into polydimethylsiloxane, Chemosphere, 73 (2008) $1575-1581$. 
[19] D. Reible, G. Lotufo, Final Report: Demonstration and Evaluation of Solid Phase Microextraction for the Assessment of Bioavailability and Contaminant Mobility, SERDP/ESTCP, Alexandria, VA, USA, 2012.

[20] D.J. Lampert, C. Thomas, D.D. Reible, Internal and external transport significance for predicting contaminant uptake rates in passive samplers, Chemosphere, 119 (2015) 910-916.

[21] Y. Choi, Y.-M. Cho, W.R. Gala, R.G. Luthy, Measurement and modeling of activated carbon performance for the sequestration of parent- and alkylated-polycyclic aromatic hydrocarbons in petroleum-impacted sediments, Environ. Sci. Technol., 47 (2013) 1024-1032.

[22] Y. Choi, Y.-M. Cho, D. Werner, R.G. Luthy, In situ sequestration of hydrophobic organic contaminants in sediments under stagnant contact with activated carbon. 2. mass transfer modeling, Environ. Sci. Technol., 48 (2014) 1843-1850.

[23] Y. Choi, Y.-M. Cho, R.G. Luthy, Polyethylene-water partitioning coefficients for parent- and alkylated-polycyclic aromatic hydrocarbons and polychlorinated biphenyls, Environ. Sci. Technol., 47 (2013) 6943-6950.

[24] K. Booij, H.E. Hofmans, C.V. Fischer, E.M. Van Weerlee, Temperature-dependent uptake rates of nonpolar organic compounds by semipermeable membrane devices and low-density polyethylene membranes, Environ. Sci. Technol., 37 (2003) 361-366. 
[25] E.M.-L Janssen, Y. Choi, R.G. Luthy, Assessment of nontoxic, secondary effects of sorbent amendment to sediments on the deposit-feeding organism Neanthes arenaceodentata, Environ. Sci. Technol., 46 (2012) 4134-4141.

[26] J.N. Huckins, J.D. Petty, K. Booij, Monitors of Organic Chemicals in the Environment, Springer, New York, NY, 2006.

[27] L.A. Fernandez, C.F. Harvey, P.M. Gschwend, Using performance reference compounds in polyethylene passive samplers to deduce sediment porewater concentrations for numerous target chemicals, Environ. Sci. Technol., 43 (2009) 88888894.

[28] R. Lohmann, Critical review of low-density polyethylene's partitioning and diffusion coefficients for trace organic contaminants and implications for its use as a passive sampler, Environ. Sci. Technol., 46 (2012) 606-618.

[29] K. Booij, J.R. Hoedemaker, J.F. Bakker, Dissolved PCBs, PAHs, and HCB in pore waters and overlying waters of contaminated harbor sediments, Environ. Sci. Technol., 37 (2003) 4213-4220.

[30] Barajas \& Associates, Inc. Final Feasibility Study Report for Parcel F. Hunters Point Shipyard, San Francisco, California, 2008.

[31] Y. Choi, Y.-M. Cho, R.G. Luthy, D. Werner, Predicted effectiveness of in-situ activated carbon amendment for field sediment sites with variable site- and compoundspecific characteristics, J. Hazard. Mater., 301 (2015) 424-432. 
